\title{
Plasma carotenoid depletion during fasting in moulting penguins
}

\author{
A. Barbosa • M. J. Palacios • J. J. Negro • \\ J. J. Cuervo
}

\begin{abstract}
The questions of whether carotenoids are mobilized from storage organs or the blood during food shortages or in stressful situations and the amount of carotenoids available in these situations remain contentious. We study the amount of carotenoids circulating in the blood stream in Gentoo Penguins (Pygoscelis papua), taking advantage of the physiological stress produced by fasting during moulting. Carotenoids are not detectable in the blood after 1 week of fasting during moulting in Gentoo Penguins, whereas breeding adults and chicks show a high concentration of astaxanthin. Our results suggest that carotenoids are consumed in physiologically stressful processes other than ornamentation.
\end{abstract}

Keywords Antarctica - Carotenoid - Fasting · Gentoo Penguin $\cdot$ Moulting $\cdot$ Pygoscelis papua

A. Barbosa $(\varangle) \cdot$ M. J. Palacios · J. J. Cuervo

Dept. Ecología Funcional y Evolutiva, Estación Experimental de Zonas Áridas, CSIC, Carretera de Sacramento s/n, 04120 La Cañada de San Urbano-Almeria, Spain

e-mail: barbosa@mncn.csic.es

Present Address:

A. Barbosa - J. J. Cuervo

Dept. Ecología Evolutiva, Museo Nacional de Ciencias

Naturales, CSIC, C/José Gutiérrez Abascal,

2, 28006 Madrid, Spain

J. J. Negro

Dept. Ecología Evolutiva, Estación Biológica de Doñana,

CSIC, C/Américo Vespucio s/n, 41092 Sevilla, Spain

\section{Zusammenfassung}

\section{Plasmakarotin-Verbrauch von mausernden Pinguinen während des Fastens}

Die Fragen, ob Karotine in Nahrungsmangelperioden oder Stresssituationen aus Speicherorganen oder dem Blut mobiliziert werden, und wie groß die in solchen Situationen verfügbare Karotinmenge ist, sind immer noch umstritten. Wir untersuchten die Karotinmenge im Blutkreislauf von Eselspinguinen (Pygoscelis papua) unter Ausnutzung des physiologischen Stresses, der durch Fasten während der Mauser entsteht. Nach einer Woche des Fastens während der Mauser ließen sich im Blut der Eselspinguine keine Karotine feststellen. Küken und brütende Altvögel wiesen hingegen hohe Konzentrationen an Astaxanthin auf. Unsere Ergebnisse legen nahe, dass Karotine in physiologischen Stress verursachenden Prozessen, die nicht der Ornamentik dienen, aufgebraucht werden.

\section{Introduction}

Carotenoids are compounds mainly synthesised by algae, higher plants or microorganisms (Goodwin 1984) that are involved in the pigmentation of ornaments in birds and other animals (Hill et al. 2002). They must have a dietary origin because of their impossibility to be synthesised by the birds (Goodwin 1984). Carotenoids are stored in organs and tissues such as the liver (McGraw and Toomey 2010) where these pigments can be metabolised and transformed before final deposition in the plumage (Del Val et al. 2009) or in body fat (Negro et al. 2001; Metzger and Bairlein 2011). However, the questions of whether carotenoids are mobilized from storage organs or the blood during food shortages 
or stressful situations, and the amounts of carotenoids available in these situations, remain contentious. The Gentoo Penguin (Pygoscelis papua) is a good model for investigating these questions because (1) these seabirds are obliged to fast during moulting because they renew all their plumage at once, which keeps them from foraging at sea due to lack of insulation; (2) krill (Euphausidae), which is a rich source of the red carotenoid astaxanthin (Yamaguchi et al. 1983), represents $90 \%$ of the diet of Antarctic penguins (Williams 1995); and (3) this species does not have coloured feathers and therefore does not need to mobilize pigments from storage organs during moulting for feather pigmentation. Astaxanthin has antioxidative and immunoestimulant properties (Miki 1991; Park et al. 2011), being more active than other carotenoids (Miki 1991; Martínez et al. 2008). Gentoo Penguins have a coloured beak which has the potential to be a secondary sexual character (Cuervo et al. 2009) and varies geographically in colour probably depending on krill abundance (Barbosa et al. 2012). Unlike feathers in which carotenoids are deposited during moulting, the outer layers of the beak are continuously replaced.

Moulting is a highly demanding activity (Groscolas and Cherel 1992) and presumably increases the production of free radicals. In addition, it also activates the immune response due to the higher risk of infection by the wounds resulting from the breakage of growing follicles (Silverin et al. 1999). Therefore, moulting in a fasting situation should produce a mobilization of carotenoids from the storage organs to the blood stream to scavenge free radicals and to enhance the immune response.

The aims of this study are to compare the levels of plasma carotenoids between a fasting (moulting) and a nonfasting (breeding) situation, and also between chicks (feeding exclusively on krill) and breeding adults (including other prey such as fish or squids in their diet).

\section{Methods}

The Gentoo Penguin has a black and white plumage but the beak and feet are red-orange. Its diet consists mainly of krill, although fish and cephalopods may also be consumed (Williams 1995). The moult occurs after breeding and lasts 15-21 days.

The study was carried out during January and February 2007 at the Stranger Point penguin rookery on King George Island, South Shetlands $\left(62^{\circ} 15^{\prime} \mathrm{S}, 58^{\circ} 37^{\prime} \mathrm{W}\right)$. Adult penguins were captured during breeding and moulting using a long-handled net. Breeding individuals were captured at their nests during guarding (between 5 and 21 January), and their chicks were taken from the nest simultaneously and kept safe from predation. When the adults and chicks had been sampled, the chicks were returned to the nest and adults released in their proximity. After release, all adults immediately resumed care of the chicks. Moulting birds (easily identified by the large amount of feathers they were losing) were captured around the colony ( 5 February). The large proportion of feathers shed indicated that birds were in late-moult, and it is highly probable that they had been fasting for at least 1 week. After sampling, birds were released in the same place where they were captured. Blood samples were taken from a foot vein with a heparinised capillary tube immediately after capture. Samples were later centrifuged at 12,000 rpm for 10 min to separate plasma from red blood cells. Plasma was frozen at $-20{ }^{\circ} \mathrm{C}$ until analysis. All samples from different penguin groups (breeding adults, moulting adults and chicks) were manipulated in the same way.

HPLC analyses were done at the Doñana Biological Station using a Jasco PU-2089 Plus instrument equipped with a quaternary pump (Jasco Analítica, Spain). Carotenoid analyses were performed using a reverse phase C18 column (Phenomenex Synergi $4 \mu$ ) and a 5- $\mu$ m particle size precolumn of the same material. Samples were pre-filtered using a nylon OEM filter $(0.45 \mu \mathrm{m}-4 \mathrm{~mm})$ and later injected with a Rheodyne 7725 i valve equipped with a $20-\mu 1$ loop (Rheodyne, Rohnent Park, CA, USA). The eluent system was as described in Mínguez-Mosquera and Hornero-Méndez (1993), except that the flow rate was $1 \mathrm{ml} / \mathrm{min}$. Data between 195 and $650 \mathrm{~nm}$ were acquired with a multiwavelength detector MD-2010 Plus (Jasco Analítica).

Quantification of carotenoids was performed using reference astaxanthin, as in a previous study by Toral et al. (2008). Known dilutions of astaxanthin were injected in the HPLC instrument to build a calibration curve at $450 \mathrm{~nm}$. Concentration of individual carotenoids was calculated from HPLC areas recorded at $450 \mathrm{~nm}$.

Astaxanthin concentrations were not normally distributed, therefore a non-parametric test was performed. Statistical analysis included Kruskal-Wallis test with status (breeding, moulting or chick) as a factor. Statistical significance was set to 0.05 .

\section{Results}

We were unable to detect any carotenoids in the blood of moulting penguins (mean $=0 \mu \mathrm{g} / \mathrm{ml}, n=25$ ), whereas breeding birds $($ mean $=15.18 \mu \mathrm{g} / \mathrm{ml}, n=43$ ) or chicks (mean $=21.91 \mu \mathrm{g} / \mathrm{ml}, \quad n=46)$ showed relatively high levels, mostly of the red carotenoid astaxanthin. The difference among groups is therefore highly significant $\left(H_{2,114}=60.52, p<0.0001\right.$, Fig. 1$)$. 


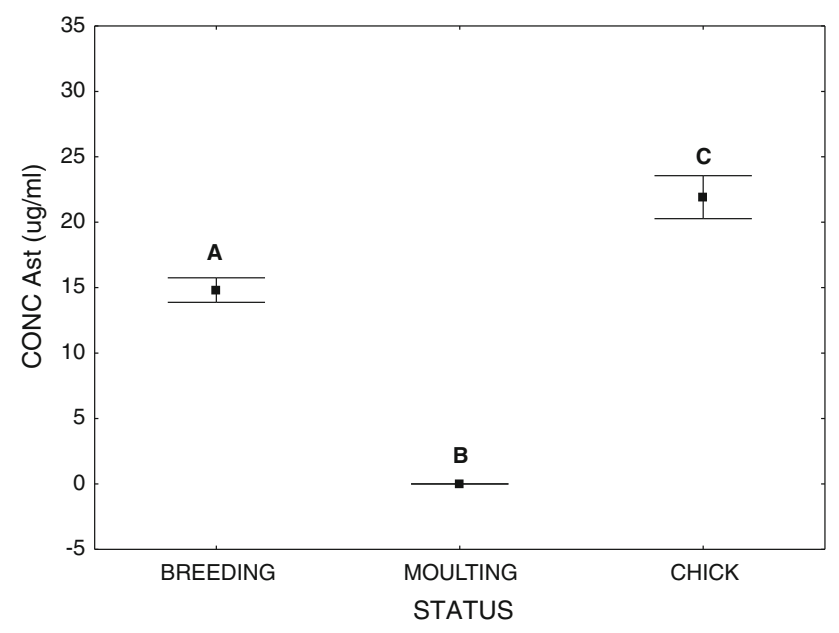

Fig. 1 Mean $( \pm$ SE) astaxanthin concentration in plasma for Gentoo Penguin (Pygoscelis papua) chicks and for adults in two different physiological situations (breeding and moulting). Different letters denote statistically significant differences $(p<0.05)$ between groups (post hoc comparisons)

\section{Discussion}

Plasma carotenoid concentration in both breeding adults and chicks were well above the average value for freeranging birds, estimated at $3.48 \mu \mathrm{g} / \mathrm{ml}$ in a subsample of 12 bird species from marine environments (Tella et al. 2004; Appendix S1). This reflects the intake of Antarctic krill as main prey, which is a rich source of the carotenoid astaxanthin. Our results show a dramatic decrease in the amount of circulating carotenoids in the blood stream during obligate fasting in moulting penguins. During this time, penguins remain ashore for at least 2 weeks because they change their entire plumage at once and this prevents them from foraging at sea. Prior to the onset of moulting, they eat and store reserves, gaining 50-70\% of body mass (Williams 1995). The total depletion of blood carotenoids in fully moulting individuals (individuals that have not eaten for at least 1 week) suggests that circulating carotenoids are used quickly, and that they are not replaced by carotenoids previously stored in organs such as the liver (del Val et al. 2009) or subcutaneous body fat (Negro et al. 2001).

Unfortunately, we did not sample individuals serially to estimate the depletion rate of blood carotenoids from a baseline prior to the onset of moult. Penguins may mobilize a large amount of fat during moulting (196-210 g/day mass loss; Adams and Brown 1990). Fat in birds is often coloured by carotenoids, and it has been suggested that carotenoids from fat may not be readily available in the blood transport system (Negro et al. 2001), although recent findings indicate that body fat is a functional carotenoid storage tissue (Metzger and Bairlein 2011). Our results can be explained in at least three different ways: (1) carotenoids are not stored in body fat in Gentoo Penguins,
(2) caroteoids cannot be mobilized from body fat in this species, or (3) carotenoids are depleted during moulting. This last explanation seems to be very likely as carotenoid mobilization from the liver has also been reported in birds (del Val et al. 2009), but we did not detect astaxanthin in the penguin blood stream of moulting penguins. Carotenoid depletion would be more likely in late stages of the moult. Although we do not know the precise time of onset of the moult in the birds that we sampled, differences in body mass between breeding and moulting individuals (the latter are $17 \%$ heavier) are in agreement with differences found between breeding and late moulting birds in other populations of the same species (i.e., $16 \%$; Williams 1990). Therefore, it is very likely that our sample was in the last stages of moulting, reinforcing the explanation for depletion. Alternatively, mobilization from the liver would be very inefficient. Another explanation might be that carotenoids need to be tied from the digestive tract. Carotenoids may just follow absorption, and as soon as there are no fats in the digestive tract, there are no carotenoids circulating in blood either. Unfortunately, we have no data to show to what extent carotenoids are stored in liver or body fat in Gentoo Penguins because this information can only be obtained from dead animals, and it is very difficult to find naturally dead adult penguins during moulting which precludes obtaining this kind of data. Finally, absence of carotenoids in the blood of moulting penguins could be explained if they are lost by excretion, but we do not think this is the case, as carotenoids which appear in the excreta have escaped from intestinal absorption but have not been excreted through the excretory system (Russell et al. 1942).

Physiological consequences of carotenoid depletion in blood could be related to a reduction in immunocompetence and an increase in oxidative stress during moulting, although alternative compounds to avoid free radicals as vitamin E could reduce the effects of carotenoid depletion. Further investigation is needed to confirm these expectations. Moreover, carotenoid depletion is expected to affect beak colouration. In fact, this is the case, as moulting birds have paler beaks than those that were breeding (Cuervo et al., unpublished).

Interestingly, chicks showed the highest levels of circulating carotenoids (see Fig. 1), possible reflecting its exclusively krill diet, while adults can incorporate other prey, such as fish or squid (Williams 1995). The large amount of circulating carotenoids in chicks compared to adults would reinforce the idea that food intake is intimately related to the level of carotenoids present in the blood stream (Hill et al. 2002).

Finally, in the present study, we measured astaxanthin on the basis that krill is the main prey for Gentoo Penguin and that krill is a rich source for this carotenoid. No other carotenoids (lutein, beta-cryptoxanthin, cantaxanthin and 
beta-caroten) were found in the blood of Gentoo Penguins from four different populations (Barbosa et al., unpublished). Therefore, we can conclude that astanxanthin is the only carotenoid present in the blood of the Gentoo Penguin.

Acknowledgments We thank the Argentine Antarctic Institute and the Carlini Antarctic Base for their hospitality. The Spanish polar ship "Las Palmas" and the Marine Technology Unit (CSIC) provided transport and logistic support. We also thank the Avian and Mammal groups of the Argentine Antarctic Institute for fieldwork assistance. Permits for working in the study area and for penguin handling were issued by the Spanish Polar Committee. Deborah Fuldauer revised the language of this manuscript. This study was funded by the Spanish Ministry of Science and Innovation and by the European Regional Development Fund (grants CGL2004-01348, POL2006-05175, CGL2007-60369 and CGL2008-00137, and specifically to JJN for carotenoid analyses, grant CGL2009-10652).

\section{References}

Adams NJ, Brown CR (1990) Energetics of moult in penguins. In: Davis LS, Darby JT (eds) Penguin biology. Academic, San Diego, pp 297-315

Barbosa A, Palacios MJ, Valera F, Martínez A (2012) Geographic variation in beak colouration in gentoo penguins Pygoscelis papua. Polar Biol 35:725-731

Cuervo JJ, Palacios MJ, Barbosa A (2009) Beak colouration as a possible sexual ornament in gentoo penguins: sexual dichromatism and relationship to body condition. Polar Biol 32: 1305-1314

del Val E, Senar JC, Garrido-Fernández J, Jaren M, Borras A, Cabrera J, Negro JJ (2009) The liver but not the skin is the site for conversion of a red carotenoid in a passerine bird. Naturwissenschaften 96:797-801

Goodwin TW (1984) The biochemistry of the carotenoids. Volume II Animals. Chapman and Hall, London

Groscolas R, Cherel Y (1992) How to molt while fasting in the coldthe metabolic and hormonal adaptations of emperor and King Penguins. Ornis Scand 23:328-334

Hill GE, Inouye CY, Montgomerie R (2002) Dietary carotenoids predict plumage colouration in wild house finches. Proc R Soc Lond B 269:1119-1124
Martínez A, Rodríguez-Gironés MA, Barbosa A, Costas M (2008) Donator aceptor map for carotenoids, melatonin and vitamins. J Phys Chem 112:9037-9042

McGraw KJ, Toomey MB (2010) Carotenoid accumulation in tissues of zebra finches: predictors of integumentary pigmentation and implications for carotenoid allocation strategies. Physiol Biochem Zool 83:97-109

Metzger BJ, Bairlein F (2011) Fat stores in a migratory bird: a reservoir in carotenoid pigments for time of need. J Comp Physiol B 181:269-275

Miki W (1991) Biological functions and activities of animal carotenoids. Pure App Chem 63:141-146

Mínguez-Mosquera MI, Hornero-Méndez D (1993) Separation and quantification of the carotenoid pigments in red peppers (Capsicum annuum L.), paprika and oleoresin by reversed-phase HPLC. J Agric Food Chem 41:1616-1620

Negro JJ, Figuerola J, Garrido J, Green AJ (2001) Fat store in birds. An overlooked sink for carotenoid pigments? Funct Ecol 15:297-303

Park JS, Mathison BD, Hayek MG, Massimino S, Reinhart GA, Chew BP (2011) Astaxanthin stimulates cell-mediated and humoral immune responses in cats. Vet Immunol Immunopathol 144:455-461

Russell WC, Taylor MV, Walker HA, Polskin LJ (1942) The absorption and retention of carotene and vitamin A by hens on normal and low fat rations. J Nutr 24:199-211

Silverin B, Frange R, Viebke PA, Westin J (1999) Seasonal changes in mass and histology of the spleen in Willow Tits Parus montanus. J Avian Biol 30:255-262

Tella JL, Figuerola J, Negro JJ, Blanco G, Rodríguez-Estrella R, Forero MG, Blázquez MC, Green AJ, Hiraldo F (2004) Ecological, morphological and phylogenetic correlates of interspecific variation in plasma carotenoid concentration in birds. J Evol Biol 17:156-164

Toral GM, Figuerola J, Negro JJ (2008) Multiple ways to become red: pigment identification in red feathers using spectrometry. Comp Biochem Physiol 150:147-152

Williams TD (1990) Annual variation in breeding biology of the gentoo penguin, Pygoscelis papua, at Bird Island, South Georgia. J Zool Lond 222:247-258

Williams TD (1995) The penguins. Oxford University Press, Oxford Yamaguchi K, Miki W, Toriu N, Kondo Y, Murakami M, Konosu S, Satake M, Fujita T (1983) Chemistry and utilization of plankton. 1. The composition of carotenoid-pigments in the Antarctic krill Euphausia superba. Bull Jpn Soc Sci Fish 49:1411-1415 